\title{
Intraoperative Radiotherapy in the Multidisciplinary Treatment of Bone Sarcomas in Children and Adolescents
}

Felipe A. Calvo, MD, PhD, David Ortiz de Urbina, MD, Luis Sierrasesúmaga, MD, $\mathrm{PhD}$, Oscar Abuchaibe, MD, Ignacio Azinovic, MD, Federico Antillon, MD, Manuel Santos, MD, and José Cañadell, MD, PhD

From the Departments of Radiation Oncology (F.A.C., D.O.d.U., O.A., LA., M.S.), Pediatric Oncology (L.S., F.A.), and Orthopedic Surgery (J.C.), Clinica Universitaria de Navarra, Facultad de Medicina, Universidad de Navarra, Navarra Spain.

Address reprint requests to Dr. Felipe A. Calvo, Department of Oncology, Clinica Universitaria de Navarra, Universidad de Navarra, Apartado 192, 31080 Pamplona (Navarra), Spain.

\section{INTRODUCTION}

Sarcomas represent a third of all malignant solid tumors in children and adolescents. The most common histological types are rabdomyosarcoma, osteosarcoma, and Ewing's sarcoma [1]. Approximately $60 \%$ of these lesions are found in bones or soft tissues of the extremities [2]. These tumors types have a high systemic dissemination capacity, and over $70 \%$ will have macro or microscopic metastases at the time of diagnosis. This implies that a combined local and systemic treatment is needed in order to reach a definitive control of the disease [3].

Multidisciplinary treatment has been employed since the 1970s, combining surgery, radiotherapy, and chemotherapy. Contemporary survival rates in patients with localized disease have been reported in the range of $65-75 \%$ for Ewing's sarcoma [4-7] and 65$90 \%$ for osteosarcoma $[8,9]$.

Local treatment of bone sarcomas of the extremities has undergone a considerable change in recent years. The tendency towards radical tumor surgical removal with amputation [11-13] has given way to programs with extremity preservation by combining surgery and neoadjuvant and adjuvant radiation therapy and chemotherapy without compromising the results in disease-free survival [14-16].

Intraoperative radiotherapy (IORT), is a treatment technique with the aim to sterilize surgically non-resected neoplastic tissue, by releasing a high dose of radiation into the tumor bed area. Some normal structures, organs, and tissues can be shielded or kept out of the irradiation field [16-19].

IORT seeks to exploit the therapeutic index by improving control over the local spread of the tumor, protecting the normal, non-affected tissues, and/or increasing the biological efficacy of irradiation after surgical debulking of the tumor [20].

Our experience using IORT in bone sarcoma patients of pediatric age is reported. 


\section{MATERIAL AND METHODS}

\section{Patients}

From September 1984 to December 1989, forty-five pediatric and adolescent patients with bone sarcomas of the extremities had entered into the prospective treatment protocol at the University Clinic of Navarra and received intraoperative radiotherapy (IORT) as a part of the multidisciplinary treatment approach. During this period a total of 51 pediatric-age patients with localized bone sarcomas were studied and treated in our institution. Five malignant fibrous histiocytomas were not analyzed in this report. One extensive Ewing's sarcoma localized in the foot was amputated as the initial radical local treatment.

Patients analyzed in this report were required to meet the following criteria: 1) histologically proven bone sarcoma diagnosis; 2) younger than 21 years; and 3) no evidence of metastatic disease at the time of diagnosis. Seven patients were excluded due to the presence of metastasis at the time of diagnosis.

Thirty-eight patients were analyzed: 22 osteosarcomas and 16 Ewing's sarcomas. Sex distribution showed 19 males and 19 females. Ages ranged from 4 to 21 years (median: 13 years). Five tumors were located in the upper extremity, 29 in the lower extremity, and 4 involved central anatomical structures. Thirty-four patients had primary disease $(90 \%)$ and 4 local tumor recurrences $(10 \%)$.

The patient characteristics by histological tumor types are detailed in Table I.

The pathology report classified the following osteosarcoma subtypes: chondroblastic [6], osteoblastic [11], fibroblastic [1], mixed [2], and other histologies [1]. Tumor characteristics are listed in Table II.

Staging procedures included computed tomography (CT) of the primary site, chest, and liver; bone scan and radiography of the chest and primary bone involved. The size of the primary tumor was measured on the pretherapy CT scan: tumor volumes were assumed to be cylindrical. The larger tumor dimension became the length of the cylinder while the smaller tumor dimension became the diameter, according to measure method described by Sailer et al. [4].

Before the initiation of the protocol, all patients were fully informed and full consent was obtained.

\section{OSTEOSARCOMA PROTOCOL}

Twenty-two patients entered this protocol, which included neoadjuvant chemotherapy with three cycles with intra-arterial cisplatinum and systemic doxorubicin, repeated every 3 weeks and followed by a wide surgical en bloc tumor-bearing resection, with an IORT boost (10-20 Gy) to the tumor bed area.

Three weeks after surgery, adjuvant chemotherapy was given using three alternating regimens, -cisplatinum-adriamycin, high-dose methotrexate, and bleomycin- 
cyclophosphamide-vincristine-actomycin $\mathrm{D}$ - and it was maintained for 48 weeks $[21,22]$.

Four patients received external beam radiotherapy because of macroscopic residual postsurgical disease: 46 Gy [3] and 50 Gy [1]. Another patient received preoperative external beam radiotherapy for a large primary tumor (25 Gy).

\section{Ewing's Sarcoma Protocol}

Primary disease. Preoperative, concurrent systemic chemotherapy and radiotherapy were used. Alternating courses of two regimens were used, containing adriamycin, methotrexate, cyclophosphamide, vincristine (regimen 1), and bleomycin, cyclophosphamide, actinomycin D, vincristine (regimen 2), every 3 weeks.

External beam radiotherapy has been delivered to a volume encompassing the entire bone and a 3-5 $\mathrm{cm}$ margin beyond the known soft tissue extension. The total dose administered has been 45-50 Gy, 1.8-2 Gy per fraction, 5 fractions per week.

Four to six weeks after completion of preoperative radiotherapy, patients were considered for surgery and an IORT boost (10-20 Gy) delivered to the residual tumor or tumor bed area.

After surgery, alternating multiagent chemotherapy was maintained according to the $\mathrm{T}_{11}$ protocol described by Rosen et al. [6] for 1 year.

Recurrent disease. Four patients with local recurrence received a reinduction course of sytemic chemotherapy followed by surgical resection plus a single IORT dose of $20 \mathrm{~Gy}$ in the tumor bed.

All patients had previously received a radical dose of external beam radiotherapy. Systemic chemotherapy was given as adjuvant therapy for 1 year or until the development of disease progression.

\section{Surgery}

Conservative surgery with limb-sparing techniques was performed on all patients: anatomic locations and radiologic extension of the tumor permitted in most cases wide excision without a severe final disability.

The methodology included a wide surgical en bloc tumor-bearing resection by removing all the involved bone and a macroscopic margin of normal surrounding tissues. It was considered radical if the margins of resection were free of tumor and if the tumorbearing bone had been completely resected. Macroscopic residual disease was considered if evidence of disease in the margins of resection or on tumor bed area was present. Treatment characteristics by histological group are related in Table III. 


\section{Intraoperative Radiotherapy (IORT)}

IORT was carried out using a linear accelerator (Mevatron 77). Single or multiple fields were used depending on anatomic location and size of the tumor bed area. Cone size ranged from 5 to $12 \mathrm{~cm}$ in diameter. The electron beam energy ranged from 6 to $20 \mathrm{~Gy}$, and it was selected depending on the tumor burden after surgery and normal tissues included in the field (Table IV). The IORT single dose ranged from 10 to $20 \mathrm{~Gy}$. The dose was adopted depending on histologic subtype, initial tumor size, and amount of postsurgical residual disease: Ewing's sarcomas were treated generally with 10 or 15 Gy, while osteosarcoma postresected tumor bed received 15 Gy (microresidue) or 20 Gy (macroresidue). This was a case-by-case decision.

The planning of each treatment program was performed by computer using a dosimetric system able to handle data and results from radiation beam calibration as well as the CT scan images.

\section{Survival and Local Control Evaluation}

Survival has been calculated from the date of initial treatment until death or last followup. Disease-free of local recurrence was measured from the date of initial treatment to the date of local relapse (within radiation field). Disease-free survival was measured from the date of initial treatment to confirmation of tumor relapse.

\section{Statistical Analysis}

Estimates of survival and survivorship free of recurrence were calculated by the KaplanMeier methods [23] using the BMDP statistical package.

\section{RESULTS}

\section{Results for the Overall Group}

Thirty-eight patients have been evaluated including 22 osteosarcomas and 16 Ewing's sarcomas. The median follow-up time was 25 months (2-65+ months). The projected 3year disease-free of local recurrence has been $93 \%$. Two patients relapsed locally. The projected 5-year disease-free survival and the overall survival for the entire group have been $65 \%$ and $69 \%$, respectively (Fig. 1).

\section{Patterns of Failure and Survival in Osteosarcoma}

Twenty-two patients with osteosarcoma have been treated and evaluated. In all cases extracompartmental involvement was present in the primary tumor, together with invasion of the surrounding soft tissues. The median follow-up time is 18 months (3+$52+$ months). Four out of 22 patients (18\%) had relapses. All of these occurred during the first 2 years after the initial treatment: 3/22 (18\%) developed lung metastasis. One out of 22 patients (chondroblastic type) had a local recurrence and distant lung metastasis 13 months after IORT. 
The 3-year projected actuarial disease-free of local recurrence and disease-free survival rates are $93 \%$ and $78 \%$, respectively. The projected actuarial survival is $87 \%$.

Twenty out of 22 patients are alive: 18/22 (81\%) with no evidence of disease and 2/22 (9\%) with metastatic disease. Two patients died from disease progression (Tables V, $\mathrm{VI})$.

\section{Patterns of Failure and Survival in Ewing's Sarcoma}

Sixteen patients with Ewing's sarcoma, primary [12] and recurrent [4], have been evaluated, with an overall median follow-up time of 24 months (3-65+ months).

Five out of 16 patients (31\%) (three primary and two recurrent) have relapsed. All developed metastatic disease progression. One local failure was identified in a patient with cervical vertebral primary.

The projected 5-year actuarial disease-free of local recurrence, disease-free survival, and overall survival were $93 \%, 58 \%$, and $57 \%$, respectively.

Nine out of 16 patients are disease free $(22+-65+$ months $)$ and 1 patient is alive with metastatic disease.

\section{Toxicity and Complications}

For the purpose of the present analysis, only those observations that might be related to IORT, or the combination of IORT with surgery and/or external beam irradiation, will be described.

At the time of the IORT procedure structures such as great vessels or nerves were mobilized or protected whenever it was possible.

\section{Early Morbidity}

Any toxic episode or complication that occurred before 3 months from IORT was considered early morbidity. Four patients had postoperative local infection requiring surgical management and removal of prosthetic devices. No further sequelae were observed.

\section{Late Morbidity}

Any complication after 3 months from IORT was considered late morbidity.

The final result regarding functional impairment was classified according to degree of functional limitation, cosmetic or radiological abnormality, dysmetry, atrophy, and peripheral neuropathy (pain, loss of sensitivity, motor deficit). 
Three patients had delayed wound healing and severe soft tissue necrosis: two patients were repaired with a myocutaneous flap, and another one required amputation after failure of several reconstructive and repair procedures.

Seven out of 38 patients (18\%) presented some degree of soft tissue fibrosis and 16/38 patients $(42 \%)$ had a mild to moderate degree of functional disability of the treated extremity. These findings were established from 6 to 12 months after IORT treatment, and were improved by an intense rehabilitation training program. No severe contractures were observed.

Six out of 38 patients $(16 \%)$ had extremity dysmetry: three of them had a shortening $>3$ $\mathrm{cm}$. All six patients received boost doses of IORT of $10 \mathrm{~Gy}$ [1], $15 \mathrm{~Gy}$ [3], and $20 \mathrm{~Gy}$ [2], and three were treated with additional external beam radiotherapy (46-50 Gy). Seven patients presented some degree of atrophy of the extremity treated.

Finally, 3/38 (8\%) patients developed a symptomatic peripheral neuropathy which occurred 9 to 13 months after IORT treatment. The associated symptoms were motor deficit, loss of discriminant sensitivity, and chronic pain. None of these cases had protection of the nerves from the IORT beam: the sciatic, femoral, and internal popliteal sciatic nerves were included in the IORT field and received 15 Gy [2] and 20 Gy [1].

Two patients showed some recovery from motor deficit starting 14 to 16 months after IORT. Chronic pain was acceptably controlled by carbamazepine, nonsteroid analgesics, and anti-inflammatory compounds (Table VII).

\section{DISCUSSION}

Local control is an essential requirement for the successful treatment of extremity bone sarcoma patients. This means that the planning of local and regional treatment must be carefully designed, taking into account in each individual case, the possible surgical options and the established chemotherapy and radiotherapy management. Factors of recognized prognostic value such as tumor stage and volume, location and involvement of the vasculo-nervous structures, presence of pathological fracture, histological grade of malignity, etc., have to be considered for treatment planning [24-28].

The multidisciplinary approach has brought significant advances in the local control of bone sarcomas, which allows more conservative attitudes in planning surgery, without detriment to the long-term survival rates $[13,29,30]$.

The addition of neoadjuvant treatment (chemotherapy with or without radiotherapy) to surgery and conservative surgery of the extremity have made possible, in many cases, tumor resection en bloc with functional reconstruction with prosthetic devices or allograft $[31,32]$.

Intra-arterial administration of chemotherapy in osteosarcoma has been shown to induce necrosis of malignant tissue with a marked reduction and delimitation in the tumor mass, thus facilitating later resection surgery [33].

Through the combination of high-dose chemo- and radiotherapy is possible to achieve up to $70 \%$ local control in Ewing's sarcoma of the extremities [5,6]. These figures are 
apparently improved by adding surgery to the treatment management, although it might be compromised in tissues which have received high irradiation doses (over 50 Gy) [26].

Intra-arterial chemotherapy and high dosage irradiation covering large anatomical areas implies a rise in toxicity in the healthy tissues surrounding the tumor which jeopardizes the normal development of the extremity, but does rescue some patients with local disease recurrences [34].

Local recurrence is noted in $10 \%$ to $30 \%$ of patients receiving combined treatment. It is most frequently seen in chondroblastic osteosarcoma, and Ewing's sarcoma of proximal locations $[27,28]$.

IORT is emerging as an interesting alternative in the attempt to sterilize the tumor bed from possible microscopic disease which remains behind at the time of maximum surgical debulking, by giving a single high dose of fast electrons (15-20 Gy) with high biological activity and cytotoxic strength [20].

In the field of pediatric oncology, IORT appears as an, interesting alternative to the use of extensive external radiation areas [35]. In selected patients it seems feasible to combine IORT (10-15 Gy) with external radiation at doses lower than have classically been considered optimal ( $15 \%$ to $25 \%$ reduction), thus reducing toxicity in healthy tissues. On the other hand, it also allows a therapeutic dose to be given in some anatomic locations with low tolerance to external radiation (e.g., paravertebral or retroperitoneal lesions) because of the proximity to highly radiosensitive critical tissues. It has also been shown as a suitable treatment modality for delivering a boost dose $[36,37]$.

In our experience, IORT is technically feasible in patients of pediatric age with locally advanced bone sarcomas. Only $2 / 38$ patients had a local progression. The projected 3 year disease-free of local recurrence rate has been $93 \%$.

Acute complications related to IORT in the immediate postoperative period have not been detected. Single doses of 10-20 Gy can be used on the extremities with safety. Preor postoperative external beam radiotherapy $(45-60 \mathrm{~Gy})$ in addition to IORT seems to increase the frequency and severity of toxicities, such as local soft tissue necrosis, peripheral neuropathy, and/or the development of long-term fibrosis of the soft tissues.

The peripheral nerves are dose-limiting structures to IORT [38]. Neuropathies have been reported after IORT treatment of retroperitoneal and pelvic tumors $[39,40]$.

The tolerance of the tissues as well as the toxicity and late morbidity of IORT trials must be carefully evaluated and reported [41]. This is of particular importance in pediatric patients.

Intraoperative radiotherapy seems to be an interesting treatment modality to promote local control in advanced primary or recurrent bone sarcomas not amenable to complete surgical resection. It appears to be an interesting approach to be considered in the management of limb-sparing surgery. Further efforts have to be made to reduce late morbidity of the extremity. 


\section{REFERENCES}

1. Young JL, Groeckler L, Silverberg E, Horm JW, Miller RW: Cancer incidence, survival, and mortality for children younger than 15 years. Cancer 58:598-602, 1986.

2. Green DM: "Diagnosis and Management of Malignant Solid 'Tumors in Infants and Children." Boston: Martins Nijhoff Publishing, 1985.

3. Rosemberg SA, Chang AE, Glatstein E: Adjuvant chemotherapy for treatment of extremity soft tissue sarcomas: Review of National Cancer Institute Experience. Cancer Treat Symp 3:283-288, 1985.

4. Sailer SL, Marimon DC, Mankin HJ, Truman JT, Suit H, Phil D: Ewing's sarcoma: surgical resection area prognostic factor. Int J Radial Oncol Biol Phys 15:43-52, 1988.

5. Jurgens H, Exner U, Gadner H, Harms D, Michaelis J, Samer R, Treuner J, Vonte T, Winkelman W, Wingler K, Gobel V: Multidisciplinary treatment of primary Ewing's sarcoma of bone. A 6 years experience of European cooperative trial. Cancer 61:23-32, 1988.

6. Rosen G, Caparros B, Nirenberg A, Marcove RC, Huvos AG, Kosloff C, Lane J, Murphy ML: Ewing's sarcoma. Ten-years experience with adjuvant chemotherapy. Cancer 47:2204-2213, 1981.

7. Nesbit ME, Jr, Perez CÁ, Tefft M, Burget EO, et al.: Multimodal therapy for the management of primary non-metastatic Ewing's sarcoma of bone. An Intergroup Study. Natl Cancer Inst Monogr 56:255-262, 1981.

8. Rosen G, Marcove RC, Huvos AG, et al.: Primary osteogenic sarcoma: Eight-year experience with adjuvant chemotherapy. J Cancer Res Clin Oncol 106:55-67, 1983.

9. Link MP, Goorin AM, Miser AW, et al.: The effect of adjuvant chemotherapy on relapse free survival in patients with osteosarcoma of the extremity. N Engl J Med 314:1600-1606, 1986.

10. Hayes FA, Thompsow EI, Meyer WH, Kun L, Parham D, Rao B, Kumar M, Hancock M, Parvey L, Magill L, Husth HO: Therapy for localized Ewing's sarcoma of bone. J Clin Oncol 7:208-213, 1989.

11. Collin Ch, Godbold J, Hajdu S, Brennan M: Localized extremity soft tissue sarcoma: An analysis of factors affecting survival. J Clin Oncol 5:601-612, 1987.

12. Simon MA, Enneking WF: The management of soft tissue sarcoma of the extremities. J Bone Joint Surg [Am] 58:317-327, 1976.

13. Eilber FR, Mirra JJ, Grant TT, et al.: Is amputation necessary for sarcoma? A seven year experience with limb salvage. Ann Surg 192:431-438, 1980.

14. Lindbergh RD, Martin RG, Romsdalh MM, et al.: Conservative surgery and postoperative radiotherapy in 300 adults with soft tissue sarcomas. Cancer 47:23912397, 1981.

15. Winkler K, Delling BG, Heise V, et al.: Neoadjuvant chemotherapy of osteosarcoma: Results of a randomized cooperative trial (COSS-82) with salvage chemotherapy based on histological tumor response. J Clin Oncol 6:329-337, 1988.

16. Abe M: Intraoperative radiotherapy: past, present and future. Int J Radiat Oncol Biol Phys 10:1987-1990, 1984.

17. Gunderson LL, Cohen AC, Dosoretz DD, et al.: Intraoperative + external beam irradiation. Curr Probl Cancer 7:1-93, 1983.

18. Kaufman BH, Gunderson LL, Evans RG, Burget JR, Gilchrist RS, Smithson NA: Intraoperative irradiation: a new technique in pediatric oncology. J Pediatr Surg 19:861,862, 1984 . 
19. Rich TA, Cady B, MacDermott WV, Kase R, Chafey JT, Hellman S: Orthovoltage intraoperative radiotherapy: a new look at and old idea. Int J Radiat Oncol Biol Phys 10:1957-1965, 1984.

20. Rich TA: Intraoperative radiotherapy. Radiother Oncol 6:207-221, 1986.

21. Sierrasesúmaga L, Martín S, Bilbao I, Calvo FA, Azcárate J, Cañadell J: Quimioterapia neoadyuvante con cisplatino intraarterial y adriamicina intravenosa más quimioterapia adyuvante. Oncología 11:80-87, 1988.

22. Rosen G, Caparros B, Huvos AG, et al.: Preoperative chemotherapy. Cancer 49:1221-1230, 1982.

23. Roday C, Rey A, Olive D, et al.: Prognostic factors in 281 children with non metastatic rhabdomyosarcoma (RMS) at diagnosis. Med Pediatr Oncol 16:71-77, 1988.

24. Raney RB, Tefft M, Maurer HM, et al.: Disease patterns and survival rates in children with metastatic soft tissue sarcoma. A report from the Intergroup Rhabdomyosarcoma Study I. Cancer 62:1257-1266, 1988.

25. Lawrence W, Jr, Edmund AG, Hays DM, Beltangady M, Mamer HM: Prognostic significance of staging factors of the UICC staging system in childhood rhabdomyosarcoma. A report from the IRS-II. J Clin Oncol 5:46-54, 1987.

26. Saver R, Jurgens H, Bugers JMV, et al.: Prognostic factors in the treatment of Ewing's sarcoma. The Ewing's Sarcoma Study Group of German Society of Pediatric Oncology CESS-81. Radiother Oncol 10:101-110, 1987.

27. Spjut HJ, Ayala AG: Skeletal tumors in children and adolescents. Hum Pathol 14:628-642, 1983.

28. Ruymann FB: Rhabdomyosarcoma in children and adolescents. A review. Hematol Oncol Clin North Am 1:621-654, 1987.

29. Limb-sparing treatment of adult soft-tissue sarcomas and osteosarcomas. Consensus conference. JAMA 254:1791-1794, 1985.

30. Rosen G, Caparros B, Niremberg A, et al.: Preoperative chemotherapy for osteogenic sarcoma. Cancer 49:1221-1230, 1982.

31. Mankin HJ, Dopplet SH, Sullivan TR, Tomfor WW: Osteoarticular intercalary allograft transplants in the treatment of malignant tumors of bone. Cancer 50:613630, 1982.

32. Marcove RC: En bloc resections for osteogenic sarcoma. Cancer Treat Rep 62:225231, 1978.

33. Jaffe N, Knapp J, Chuang VP, et al.: Osteosarcoma: Intraarterial treatment of the primary tumor with cisdiamnine dichloroplatinum II. Angiographic, pathologic and pharmacologic studies. Cancer 51:402-407, 1983.

34. Parker RA, Berry HC: Late effects of therapeutic irradiation on the skeleton and bone marow. Cancer 37:1162-1171, 1976.

35. Calvo FA, Sierrasesúmaga L, Martin I, Santos M, Voltas J, Berián JM, Cañadell J: Intraoperative radiotherapy in the multidisciplinary treatment of pediatric tumors. A preliminary report on initial results. Acta Oncol 28:257-260, 1989.

36. Calvo FA, Hanks GE: Intraoperative trials. Int J Radial Oncol Biol Phys 14:S111S117, 1988.

37. Sindelar WF, Kinsella TJ: Intraoperative radiotherapy. In De Vita VT, Hellman S, Rosemberg SA (eds): "Cancer. Principies and Practice of Oncology." Philadelphia: JB Lippincott Co., 1985, pp. 2293-2304.

38. Kinsella TJ, Sindelar WF, DeLuca DM, Terrill L: Tolerance of peripheral nerve to intra-operative radiotherapy. Clinical and experimental studies. Int J Radiat Oncol Biol Phys 10:80-84, 1984. 
39. Kinsella TJ, Sindelar WF, Lack E, Glastein E, Rosemberg SA: Preliminary results of a randomized study of adjuvant radiation therapy in resectable adult retroperitoneal soft tissue sarcomas. J Clin Oncol 6:18-25, 1988.

40. Shaw EG, Gunderson LL, Martin JK, Beart RW, Nagorney DW, Podratz KC: Peripheral nerve and ureteral tolerance to intraoperative radiation therapy: clinical and dose-response analysis. Radiother Oncol 18:247-255, 1990.

41. Tepper JE, Gunderson LL, Goldson AL, et al.: Quality control parameters of intraoperative radiotherapy. Int J Radial Oncol Biol Phys 12:1687-1695, 1986. 


\begin{tabular}{|c|c|c|}
\hline \multicolumn{3}{|c|}{ Table 1. Patient Characteristics } \\
\hline & Osteogenic sarcoma & Ewing's sarcoma \\
\hline No. of patients & 22 & 16 \\
\hline Age (yr) & 11 & 14 \\
\hline Median & $6-19$ & $4-21$ \\
\hline Range & & 9 \\
\hline Sex & 10 & 7 \\
\hline Male & 12 & 12 \\
\hline Female & 16 & 4 \\
\hline Karnofsky & 6 & 20 months \\
\hline$\geq 70 \%$ & 18 months & $(2-65+)$ \\
\hline$<70 \%$ & $(3+-52+)$ & \\
\hline Median follow-up & & \\
\hline Range &
\end{tabular}

\begin{tabular}{|c|c|c|}
\hline \multicolumn{3}{|c|}{ Table 2. Tumor Characteristics } \\
\hline Tumor & Osteogenic sarcoma & Ewing's sarcoma \\
\hline Involved bones & & \\
\hline Extremity & & 1 \\
\hline Humerus & 3 & 3 \\
\hline Femur & 14 & 4 \\
\hline Tibia & 5 & 3 \\
\hline Fibula & & 1 \\
\hline Radium & & 2 \\
\hline Central & & 2 \\
\hline Vertebra & & 9 \\
\hline Pelvis & & 7 \\
\hline Tumor size $\left(\mathrm{cm}^{3}\right)$ & 13 & 12 \\
\hline$\leq 300$ & 9 & 4 \\
\hline$>300$ & & \\
\hline Type of disease & & \\
\hline Primary & & \\
\hline Recurrent & & \\
\hline
\end{tabular}




\begin{tabular}{|c|c|c|c|c|}
\hline \multicolumn{5}{|c|}{ Table 3. Treatment Characteristics } \\
\hline \multirow[t]{2}{*}{ Treatment } & \multicolumn{2}{|c|}{ Osteogenic sarcoma } & \multicolumn{2}{|c|}{ Ewing's sarcoma } \\
\hline & No. & $(\%)$ & No. & $(\%)$ \\
\hline \multicolumn{5}{|l|}{ Chemotherapy } \\
\hline Neoadjuvant chemotherapy & 22 & $(100)$ & 16 & $(100)^{\mathrm{a}}$ \\
\hline Adjuvant chemotherapy & 22 & $(100)$ & 16 & $(100)^{\mathrm{a}}$ \\
\hline \multicolumn{5}{|l|}{ Surgery } \\
\hline Macroscopic residual disease & 4 & (18) & 5 & (31) \\
\hline Microscopic residual disease & 18 & $(81)$ & 11 & (69) \\
\hline \multicolumn{5}{|l|}{ Radiotherapy } \\
\hline Preoperative & 1 & (4) & 5 & (31) \\
\hline Postoperative & 4 & $(18)$ & 3 & (18) \\
\hline Pre- and postoperative & - & & 3 & (18) \\
\hline
\end{tabular}

\begin{tabular}{|c|c|c|}
\hline \multicolumn{3}{|c|}{ Table 4. IORT Treatment Characteristics } \\
\hline IORT & Osteogenic sarcoma & Ewing's sarcoma \\
\hline \multicolumn{3}{|c|}{ Cone size $(\mathrm{cm})$} \\
\hline $5-8$ & 8 & 11 \\
\hline $9-12$ & 19 & 10 \\
\hline \multicolumn{3}{|c|}{ Electron energy $(\mathrm{MeV})$} \\
\hline $6-9$ & 21 & 15 \\
\hline $12-20$ & 6 & 6 \\
\hline \multicolumn{3}{|c|}{ Total dose (Gy) } \\
\hline 10 & 5 & 11 \\
\hline 15 & 13 & 9 \\
\hline 20 & 9 & 1 \\
\hline \multicolumn{3}{|l|}{ No. of fields } \\
\hline Single & 17 & 13 \\
\hline Multiple & 5 & 3 \\
\hline \multicolumn{3}{|c|}{$\begin{array}{l}\text { a Osteogenic sarcoma: } 5 \text { patients were treated with a double Ewing's } \\
\text { sarcoma: } 2 \text { patients were treated with a double field and } 1 \text { patient was } \\
\text { treated with four consecutive fields }\end{array}$} \\
\hline
\end{tabular}


Table 5. Patterns of Failure*

\begin{tabular}{l|c|c|c|}
\hline Disease & LF & LF + DM & DM \\
\hline Osteosarcoma & $0 / 22$ & $1 / 22$ & $3 / 22$ \\
\hline Ewing's sarcoma & & & $2 / 12$ \\
\hline \multicolumn{1}{|c|}{ Primary } & $0 / 12$ & $1 / 12$ & $2 / 4$ \\
\hline Recurrent & $0 / 4$ & $0 / 4$ & \\
\hline *LF, local failure; DM, distant metastasis.
\end{tabular}

\begin{tabular}{|l|c|c|c|c|}
\hline \multicolumn{5}{|c|}{ Table 6. Local control and Patient Outcome* } \\
\hline Disease & No. patients & MFT (mo) & $\begin{array}{c}\text { Local } \\
\text { control }\end{array}$ & $\begin{array}{c}\text { Patient's status } \\
\text { (alive/dead) }\end{array}$ \\
\hline Osteosarcoma & 22 & $18+$ & $21 / 22(95 \%)$ & $20 / 2$ \\
\hline Ewing's sarcoma & & & & $10 / 2$ \\
\hline Primary & 11 & $35+$ & $11 / 12(92 \%)$ & $0 / 4$ \\
\hline Recurrent & 4 & 12 & $4 / 4(100 \%)$ & \\
\hline \multicolumn{5}{|c|}{$*$ MFT = median follow up time (mo) } \\
\hline
\end{tabular}

Table 7. Late Morbidity Due to the Treatment Program Including the Possible IORT

\begin{tabular}{|c|c|c|c|}
\hline Toxicity & IORT & EBR & Outcome \\
\hline \multirow{2}{*}{$\begin{array}{l}\text { Delayed wound healing } \\
\text { and necrosis }\end{array}$} & 10 & 10 (preop) & \multirow{2}{*}{$\begin{array}{l}\text { Reversible-myocutaneous } \\
\text { flap }\end{array}$} \\
\hline & & 46 (postop) & \\
\hline \multirow{2}{*}{$\begin{array}{l}\text { Delayed wound healing } \\
\text { and necrosis }\end{array}$} & 15 & 10 (preop) & \multirow{2}{*}{$\begin{array}{l}\text { Reversible-myocutaneous } \\
\text { flap }\end{array}$} \\
\hline & & 46 (postop) & \\
\hline \multirow{2}{*}{$\begin{array}{l}\text { Delayed wound healing and } \\
\text { necrosis }\end{array}$} & 10 & 10 (preop) & Amputation \\
\hline & & 46 (postop) & \\
\hline Severe fibrosis & 15 & 46 & Loss of movement at hip \\
\hline $\begin{array}{l}\text { Severe fibrosis + peripheral } \\
\text { neuropathy }\end{array}$ & 15 & - & Slowly reversible at 14 months \\
\hline $\begin{array}{l}\text { Severe fibrosis + peripheral } \\
\text { neuropathy }\end{array}$ & 15 & - & Slowly reversible at 16 months \\
\hline Peripheral neuropathy & 20 & - & No recovery \\
\hline Shortening $>3 \mathrm{~cm}$ & 10 & 46 & Modera te disability \\
\hline Shortening $>3 \mathrm{~cm}$ & 20 & - & Modera te disability \\
\hline Shortening $>3 \mathrm{~cm}$ & 15 & 50 & Severe disability \\
\hline
\end{tabular}




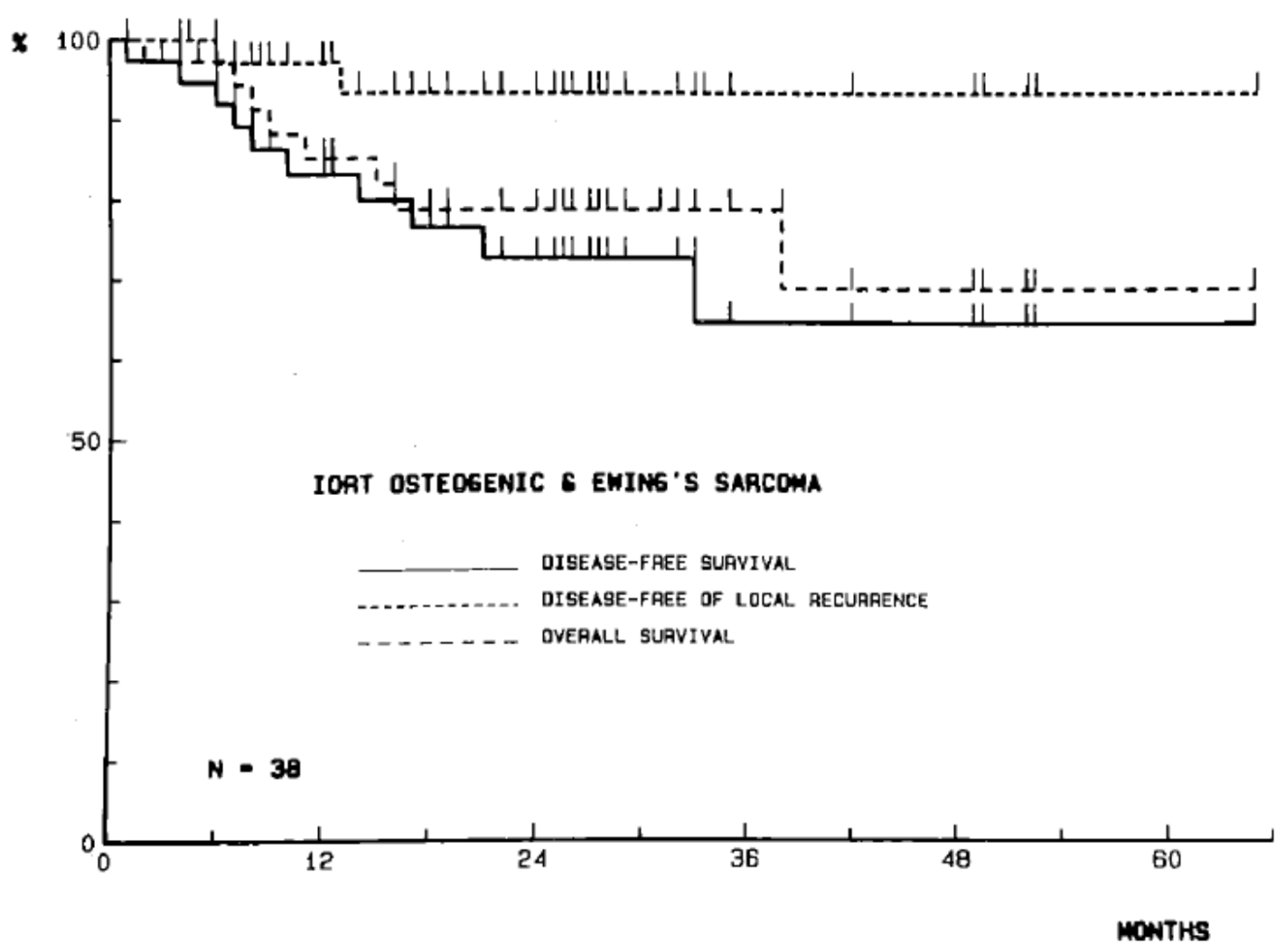

Figure 1. Disease-free survival, disease-free of local recurrence, and overall survival for the entire group. 